\title{
Supporting information for Marine productivity and synoptic meteorology drive summer-time variability in Southern Ocean aerosols
}

Joel Alroe ${ }^{1}$, Luke T. Cravigan ${ }^{1}$, Branka Miljevic ${ }^{1}$, Graham R. Johnson ${ }^{1}$, Paul Selleck ${ }^{2}$, Ruhi S. 5 Humphries $^{2}$, Melita D. Keywood ${ }^{2}$, Scott D. Chambers ${ }^{3}$, Alastair G. Williams ${ }^{3}$ and Zoran D. Ristovski ${ }^{1}$

${ }^{1}$ School of Chemistry, Physics and Mechanical Engineering, Queensland University of Technology, Brisbane, Australia

${ }^{2}$ Climate Science Centre, CSIRO Oceans and Atmosphere, Aspendale, Australia

${ }^{3}$ Environmental Research, ANSTO, Lucas Heights, Australia

Correspondence to: Zoran D. Ristovski (z.ristovski@qut.edu.au)

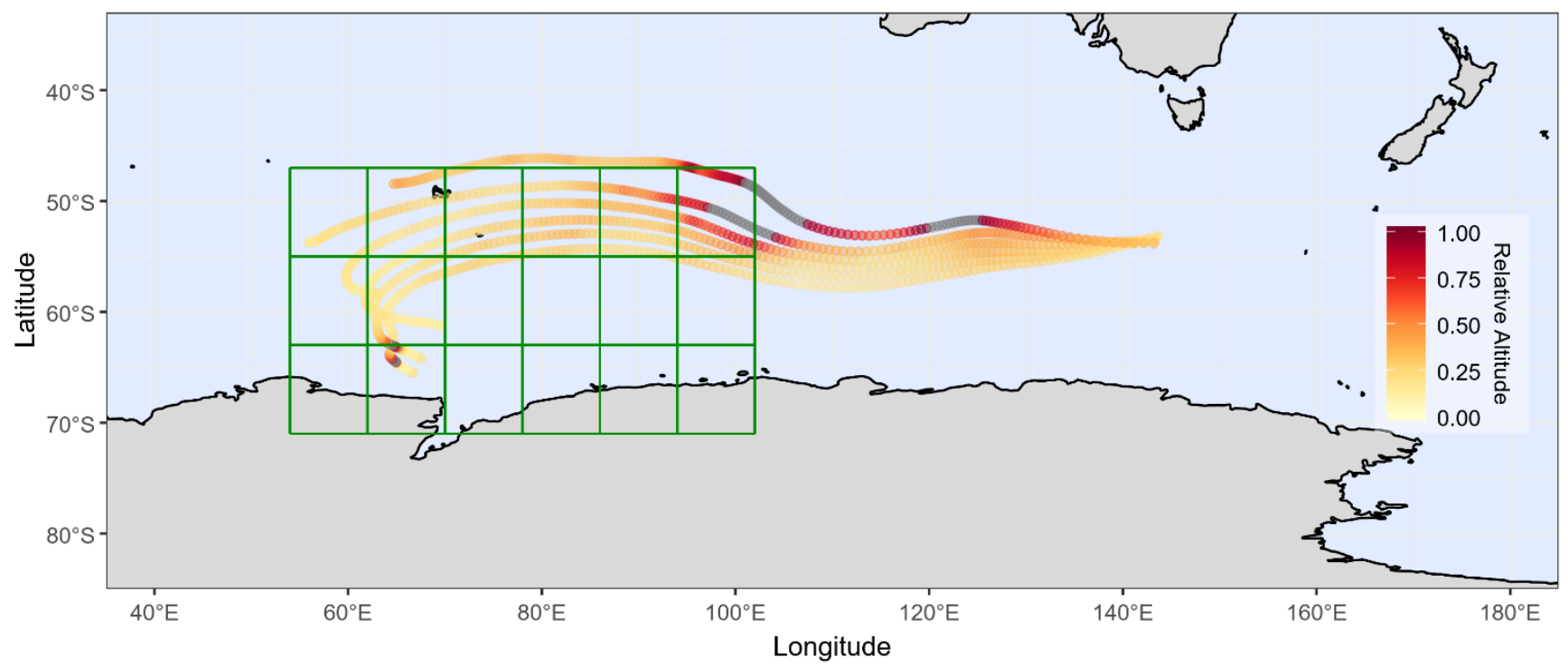

Figure S1: Example 7-day back trajectories for air masses which reached the RV Investigator at hourly intervals between between 0000 and 0600 (UTC) on 4 February 2015. An ensemble of 27 back trajectories were generated for each air mass and the depicted trajectories represent the mean of each ensemble. Data points represent the air mass location at each hour along the back trajectory. The colour scale gives the altitude of the air mass relative to the estimated boundary layer, and grey data points represent hours when the air mass passed into the free troposphere. The green grid demonstrates the rasterization scheme applied to the biologically productive region between the Kerguelen Plateau and the Antarctic coastline. Similar back trajectory plots are available for the full voyage (1st - 15th February 2015) on request. 
Table S1: Mean physical properties observed for each air mass encountered throughout the voyage. Uncertainties have been taken from the standard deviations.

\begin{tabular}{|c|c|c|c|c|c|c|c|}
\hline Air mass & mSO1 & $c A U$ & mSO2 & cAA1 & mSO3 & cAA2 & mSO4 \\
\hline Latitude extents & $43.3-54.0^{\circ} \mathrm{S}$ & $54.2-58.8^{\circ} \mathrm{S}$ & $59.3-64.0^{\circ} \mathrm{S}$ & $64.0-65.1^{\circ} \mathrm{S}$ & $59.9-64.1^{\circ} \mathrm{S}$ & $57.5-59.9^{\circ} \mathrm{S}$ & $46.1-57.5^{\circ} \mathrm{S}$ \\
\hline \multicolumn{8}{|c|}{ Number concentrations } \\
\hline $\mathrm{N}_{10}\left(\mathrm{~cm}^{-3}\right)$ & $390 \pm 120$ & $220 \pm 70$ & $500 \pm 110$ & $310 \pm 40$ & $510 \pm 160$ & $310 \pm 34$ & $680 \pm 210$ \\
\hline $\mathrm{CCN}_{0.5 \%}\left(\mathrm{~cm}^{-3}\right)$ & $200 \pm 60$ & $180 \pm 65$ & $204 \pm 100$ & $240 \pm 36$ & $162 \pm 48$ & $180 \pm 40$ & $200 \pm 35$ \\
\hline $\mathrm{CCN}_{0.5 \%}$ activation ratio & $0.52 \pm 0.15$ & $0.79 \pm 0.11$ & $0.40 \pm 0.17$ & $0.79 \pm 0.06$ & $0.34 \pm 0.14$ & $0.60 \pm 0.11$ & $0.37 \pm 0.14$ \\
\hline \multicolumn{8}{|c|}{ Size distributions } \\
\hline Aitken number fraction & $0.61 \pm 0.15$ & $0.40 \pm 0.07$ & $0.74 \pm 0.10$ & $0.30 \pm 0.07$ & $0.74 \pm 0.10$ & $0.56 \pm 0.14$ & $0.76 \pm 0.13$ \\
\hline Aitken mean diameter (nm) & $32 \pm 7$ & $43 \pm 11$ & $31 \pm 5$ & $35 \pm 7$ & $22 \pm 3$ & $25 \pm 7$ & $31 \pm 5$ \\
\hline $\begin{array}{l}\text { Accumulation mean diameter } \\
(\mathrm{nm})\end{array}$ & $145 \pm 30$ & $191 \pm 18$ & $128 \pm 21$ & $110 \pm 15$ & $143 \pm 19$ & $122 \pm 9$ & $133 \pm 20$ \\
\hline Hoppel minimum diameter $(\mathrm{nm})$ & $73 \pm 11$ & $76 \pm 7$ & $68 \pm 5$ & $56 \pm 9$ & $66 \pm 6$ & $59 \pm 6$ & $68 \pm 5$ \\
\hline \multicolumn{8}{|c|}{ Hygroscopicity } \\
\hline KD40 & $\mathrm{NA}^{1}$ & $0.38 \pm 0.09$ & $0.35 \pm 0.06$ & $0.33 \pm 0.03$ & $0.41 \pm 0.13$ & $0.50 \pm 0.06$ & $0.39 \pm 0.07$ \\
\hline$\kappa_{\mathrm{D} 100}$ & NA & $0.37 \pm 0.04$ & $0.45 \pm 0.08$ & $0.35 \pm 0.08$ & $0.49 \pm 0.08$ & $0.42 \pm 0.06$ & $0.40 \pm 0.07$ \\
\hline$\kappa_{\mathrm{D} 150}$ & NA & $0.46 \pm 0.07$ & $0.63 \pm 0.11$ & $0.50 \pm 0.11$ & $0.55 \pm 0.07$ & $0.51 \pm 0.13$ & $0.46 \pm 0.10$ \\
\hline \multicolumn{8}{|c|}{ Volatility } \\
\hline $\mathrm{VFR}_{\mathrm{D} 40}$ & NA & $0.89 \pm 0.03$ & $0.82 \pm 0.11$ & $1.04 \pm 0.05$ & $0.97 \pm 0.09$ & $0.91 \pm 0.07$ & $0.91 \pm 0.09$ \\
\hline VFRD100 & NA & $0.85 \pm 0.03$ & $0.89 \pm 0.10$ & $0.97 \pm 0.08$ & $0.95 \pm 0.04$ & $0.92 \pm 0.06$ & $0.88 \pm 0.06$ \\
\hline VFR $_{\mathrm{D} 150}$ & NA & $0.92 \pm 0.02$ & $0.89 \pm 0.08$ & $0.91 \pm 0.13$ & $0.99 \pm 0.03$ & $0.95 \pm 0.03$ & $0.89 \pm 0.05$ \\
\hline \multicolumn{8}{|c|}{ Composition } \\
\hline $\operatorname{Org}\left(\mu \mathrm{g} \mathrm{m}^{-3}\right)$ & $\mathrm{BDL}^{2}$ & $0.08 \pm 0.05$ & BDL & $\mathrm{BDL}$ & BDL & BDL & BDL \\
\hline $\mathrm{SO}_{4}\left(\mu \mathrm{g} \mathrm{m}^{-3}\right)$ & $0.11 \pm 0.07$ & $0.18 \pm 0.08$ & $0.09 \pm 0.03$ & $0.12 \pm 0.03$ & $0.09 \pm 0.04$ & $0.12 \pm 0.03$ & $0.17 \pm 0.05$ \\
\hline $\operatorname{SSA}\left(\mu \mathrm{g} \mathrm{m}^{-3}\right)$ & $0.10 \pm 0.07$ & $0.12 \pm 0.10$ & $0.10 \pm 0.05$ & $0.03 \pm 0.02$ & $0.28 \pm 0.19$ & $0.14 \pm 0.05$ & $0.39 \pm 0.18$ \\
\hline \multicolumn{8}{|c|}{ Continental / anthropogenic influences } \\
\hline Radon $\left(\mathrm{mBq} \mathrm{m} \mathrm{m}^{-3}\right)$ & $30 \pm 19$ & $83 \pm 38$ & $46 \pm 11$ & $81 \pm 25$ & $44 \pm 14$ & $62 \pm 13$ & $49 \pm 17$ \\
\hline $\mathrm{BC}\left(\mathrm{ng} \mathrm{m}^{-3}\right)$ & $5 \pm 6$ & $12 \pm 6$ & $5 \pm 4$ & $4 \pm 7$ & $8 \pm 7$ & $3 \pm 1$ & $3 \pm 6$ \\
\hline
\end{tabular}

${ }^{1}$ Not available

${ }^{2}$ Below detection limit 


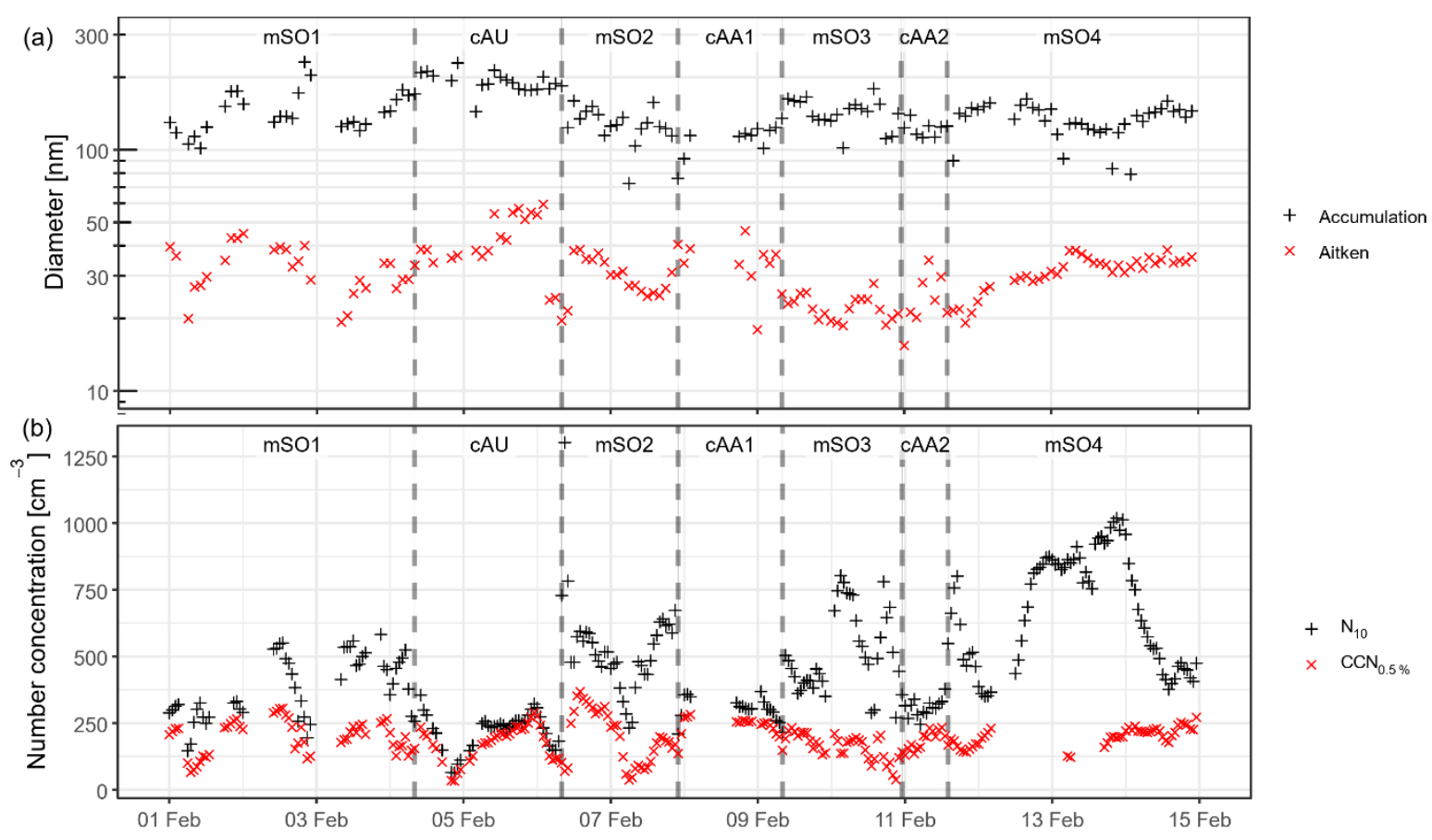

Figure S2: (a) Geometric mean diameters of aerosol in the Aitken and accumulation mode. (b) Concentrations of aerosol with diameters larger than $10 \mathrm{~nm}$ and CCN concentrations at $0.5 \%$ supersaturation. Periods influenced by different air masses are labelled and delimited by dotted lines. 


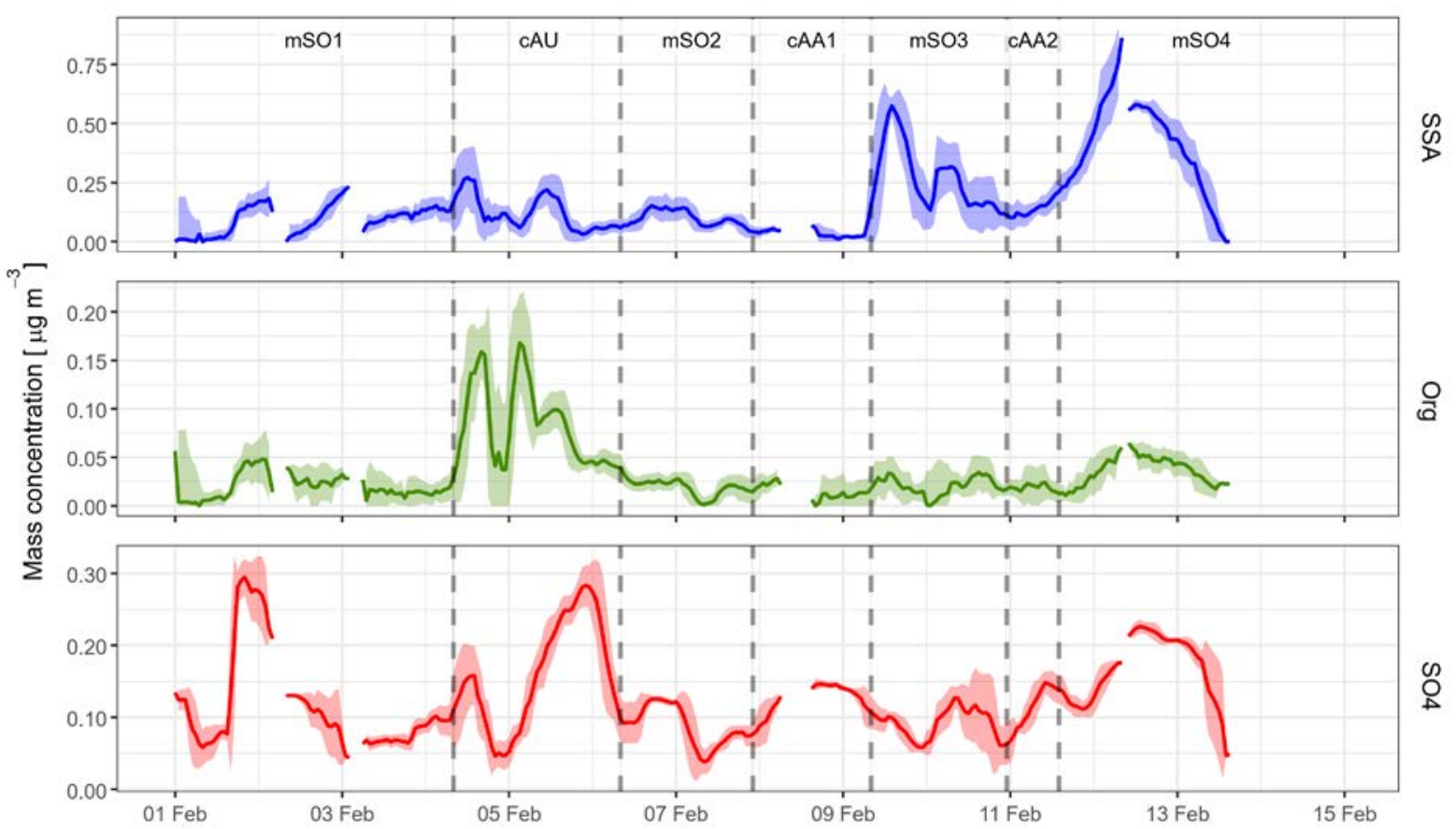

Figure S3: Mass concentrations of the dominant compositional species observed in sub-micron aerosol throughout the voyage. A six-hour rolling average has been applied to assist in identification of temporal trends. The shaded regions represent the standard deviation within each six-hour average. Periods influenced by different air masses are labelled 5 and delimited by dotted lines.

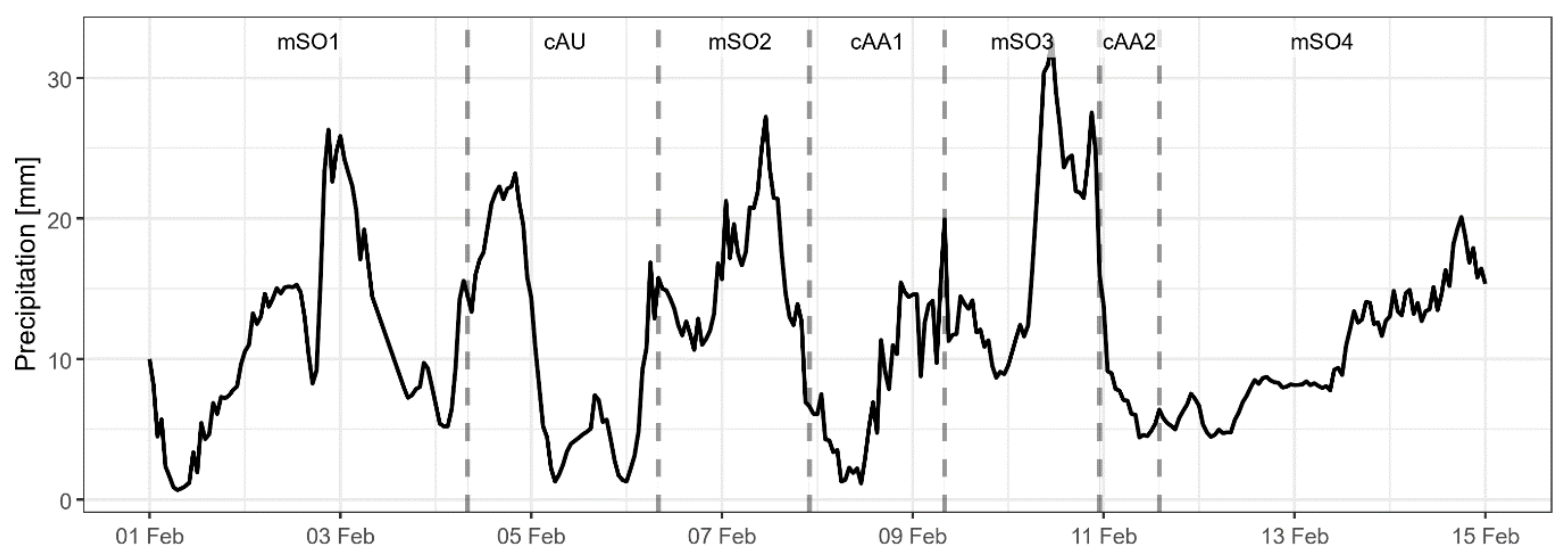

Figure S4: Estimated total rainfall experienced by air masses along their respective 7-day back trajectories prior to reaching the ship. Air mass locations and corresponding precipitation rates were determined on an hourly basis from ensembles of 27 back trajectories generated with the HYSPLIT modelling system. Periods influenced by different air masses are labelled and delimited by dotted lines. 


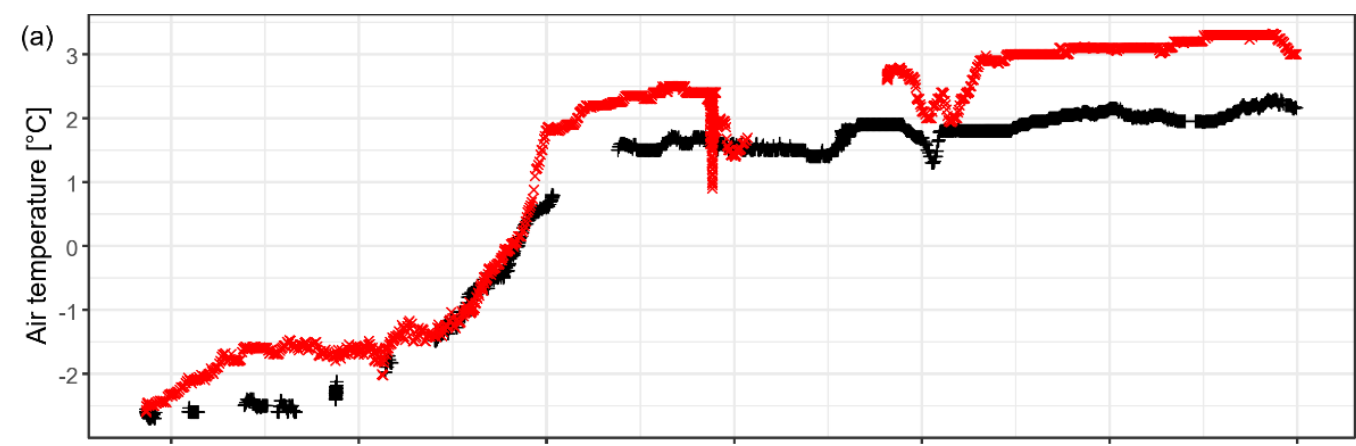

Direction

+ Southward

$\times$ Northward

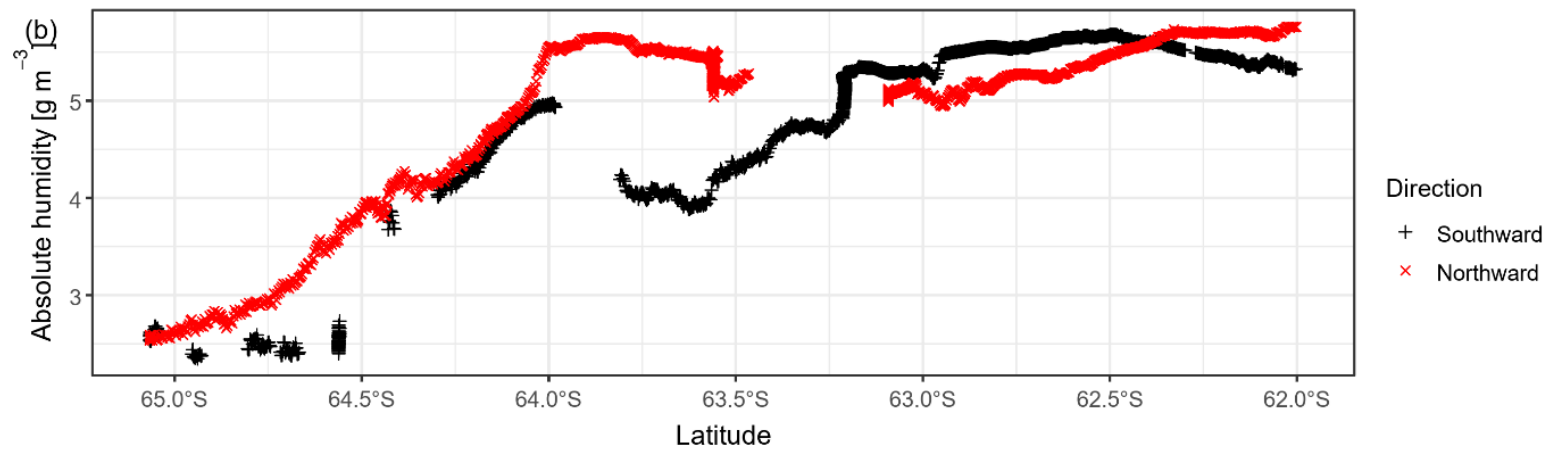

Figure S5: Meteorological observations at the southern-most extent of the voyage, demonstrating a pronounced decrease in air temperature (a) and absolute humidity (b) below $64{ }^{\circ} \mathrm{S}$, likely indicating a transition from the Ferrel atmospheric cell into the colder and dryer polar cell.

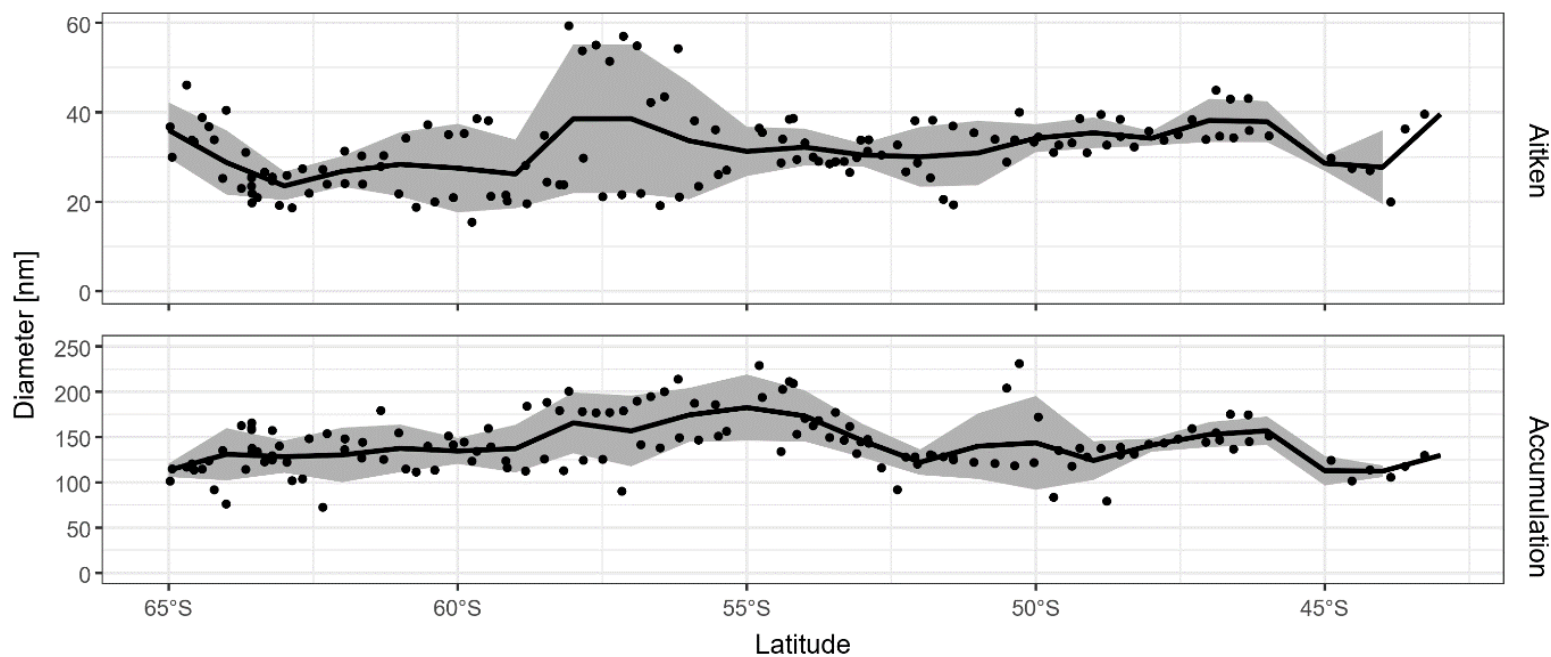

Figure S6: Geometric mean diameters of the Aitken and accumulation modes fitted to the particle number size distributions for the full latitudinal range of the Cold Water Trial voyage. Data points are 2-hourly mean observations, while the black lines represent latitude-averaged diameters at a $1^{\circ}$ resolution. The shaded regions represent the 
corresponding standard deviation of the latitudinal averages and blank regions indicate insufficient data to calculate a standard deviation.
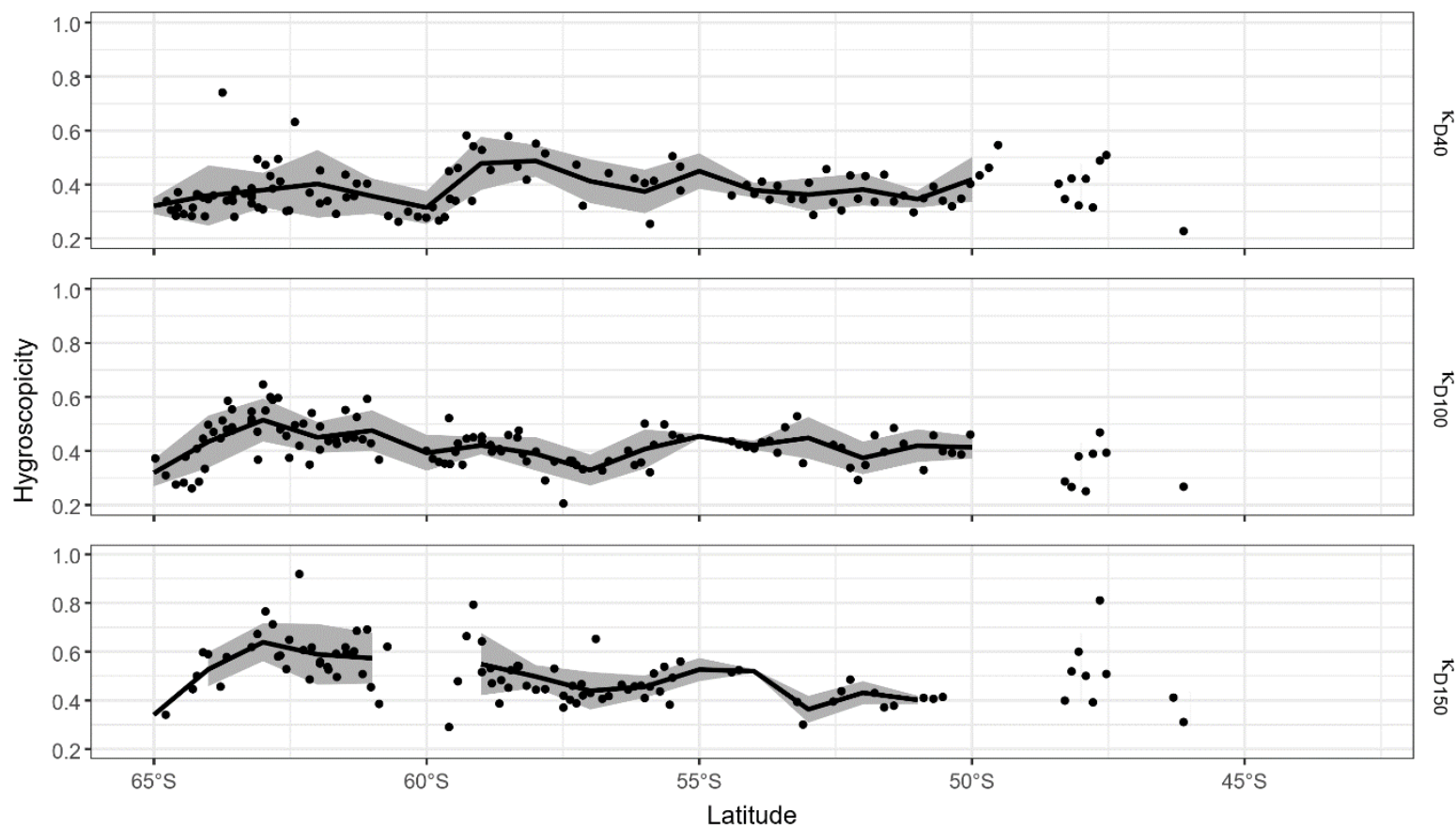

Figure S7: Aerosol hygroscopicity as observed across the full latitudinal range of the Cold Water Trial voyage, for particles with dry diameters of 40,100 and $150 \mathrm{~nm}$. Data points are hourly mean observations, while the black lines represent latitude-averaged concentrations at a $1^{\circ}$ resolution. The shaded regions represent the corresponding standard deviation of the latitudinal averages and blank regions indicate insufficient data to calculate a standard deviation. Minimal observations are available at latitudes north of $50^{\circ} \mathrm{S}$ due to instrument failure and contamination from ship emissions. 


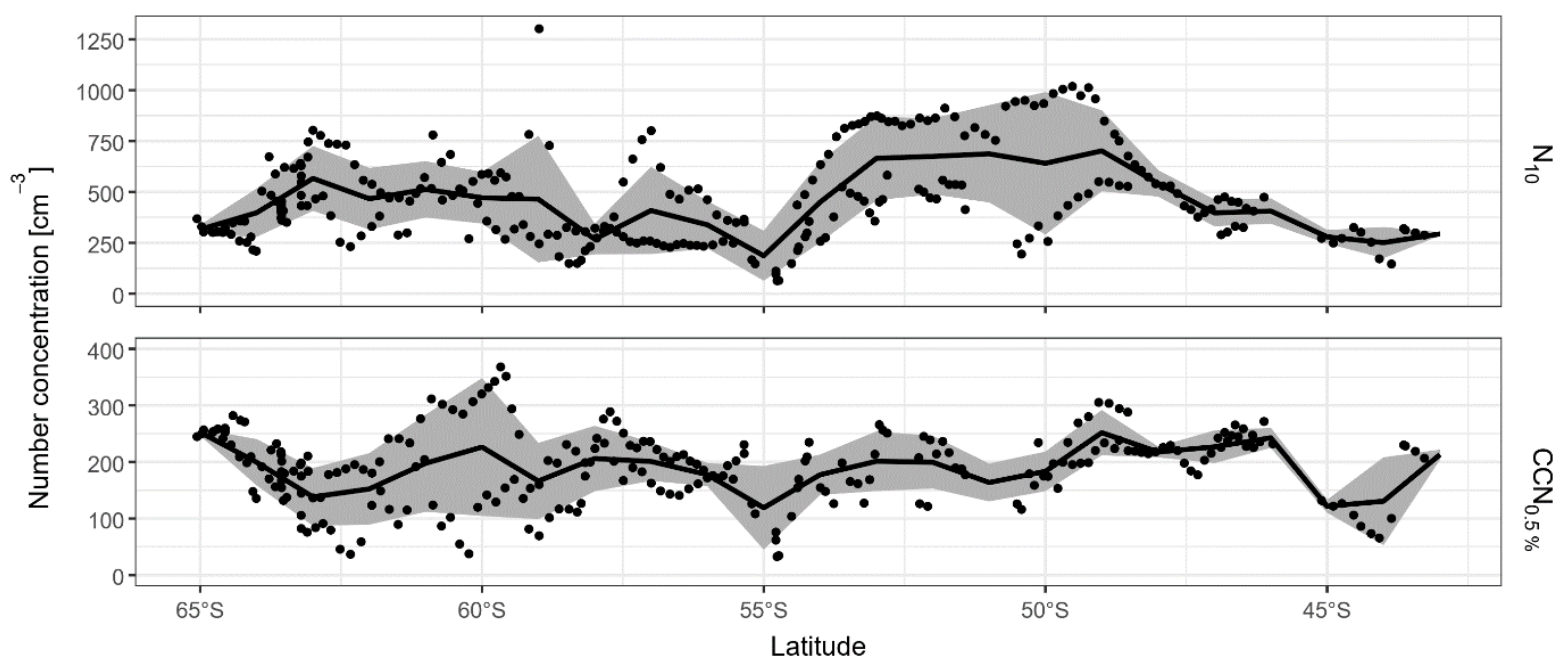

Figure S8: Concentrations of aerosol with diameters larger than $10 \mathrm{~nm}$ and cloud condensation nuclei measured $\mathbf{0 . 5 \%}$ supersaturation as observed across the full latitudinal range of the Cold Water Trial voyage. Data points are hourly mean observations, while the black lines represent latitude-averaged concentrations at a $1^{\circ}$ resolution. The shaded regions represent the corresponding standard deviation of the latitudinal averages.

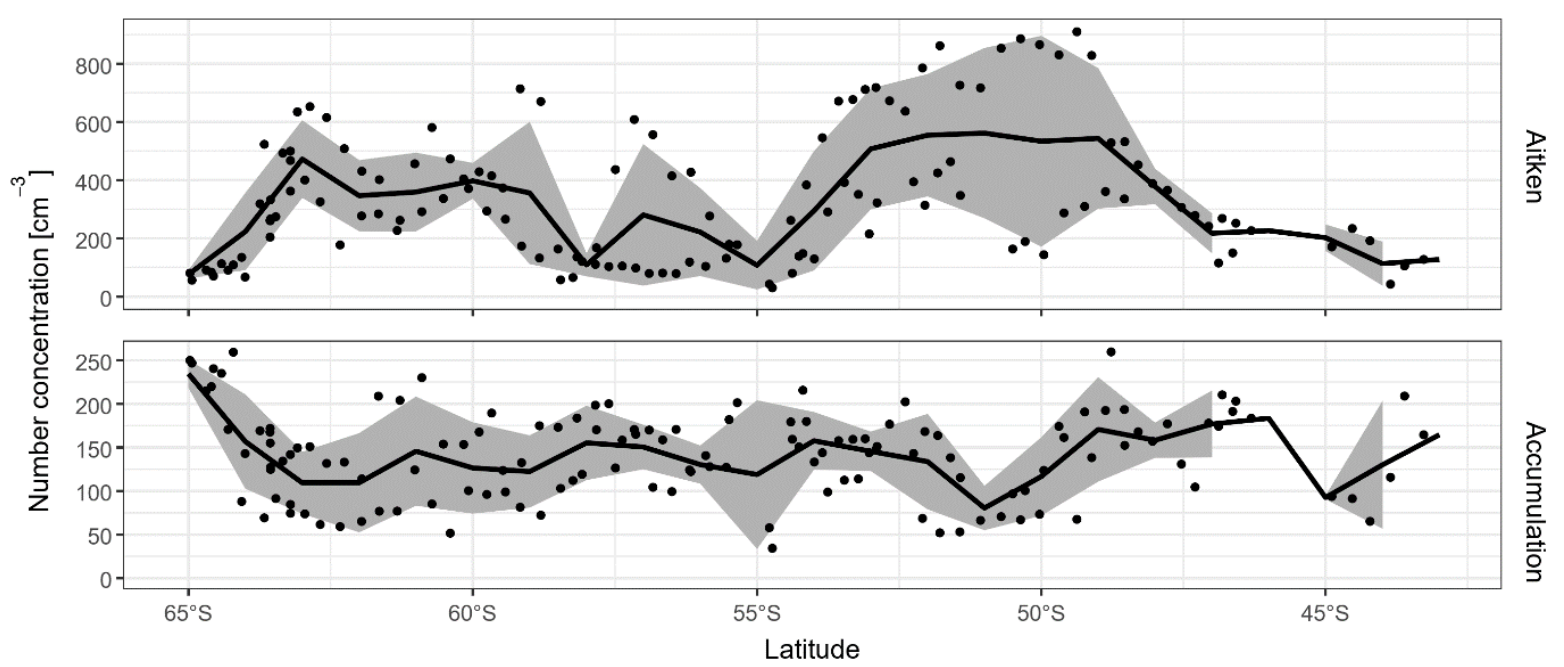

Figure S9: Concentrations of Aitken and accumulation mode aerosol as observed across the full latitudinal range of the Cold Water Trial voyage. Data points are hourly mean observations, while the black lines represent latitudeaveraged concentrations at a $1^{\circ}$ resolution. The shaded regions represent the corresponding standard deviation of the latitudinal averages and blank regions indicate insufficient data to calculate a standard deviation. 